\title{
Agricultural workers in a cohort of middle-aged Japanese women showed better health status than did women with other occupations
}

\author{
Hisaka lijima ${ }^{1}$, Shosuke Suzuki ${ }^{1}$, Hiroshi Koyama ${ }^{2}$, Minato Nakazawa ${ }^{3}$, and Yuji Wakimoto ${ }^{1}$ \\ ${ }^{1}$ International Eco-Health Research Group, Japan \\ ${ }^{2}$ Department of Public Health, Gunma University Graduate School of Medicine, Japan \\ ${ }^{3}$ Department of International Health, Kobe University Graduate School of Health Sciences, Japan
}

\begin{abstract}
Objective: This study investigated the relationship between occupations and health status to obtain an overall understanding of a cohort of Japanese middle-aged women, including unemployed women, who comprised approximately $30 \%$ of the sample.

Participants and Methods: Participants of this study were 4,454 women aged 40-69 years, classified into the following five groups based on their occupation: unemployed, 1,432; agriculture, 439; self-employed, 1,596; white collared, 793; and blue collared, 194. Participants' perceived health was assessed using a symptoms checklist called the Todai Health Index (THI, later renamed as the Total Health Index) in a baseline survey conducted in 1993. The mortality risk of the participants was assessed using the Cox's Proportional Hazards Model.

Results: The means of the percentile values on the Total Scale 1 in the THI were as follows: agriculture, 43.7; unemployed, 50.8; self-employed, 52.5; white collared, 53.0; and blue collared, 56.1, with lower percentile values indicating better perceived health. The results showed that women engaged in agriculture were in significantly better health than were those in the other four occupations. The hazard ratios (HRs) and 95\% confidence intervals of the occupational groups adjusted for age, area of residence, and Total Scale 1 scores were as follows: agriculture (reference group), 1; white collared, 1.16 (0.77-1.74); self-employed, 1.25 (0.87-1.78); unemployed, 1.27 (0.91-1.77); and blue collared, 1.50 (0.86-2.60).

Conclusions: Women engaged in agriculture had a significantly higher tendency to have a better health status on the THI as com-
\end{abstract}

Received: July 11, 2017

Accepted: February 8, 2018

Correspondence: Hisaka Iijima, International Eco-Health Research Group, Horiguchi 133-4, Isesaki, Gunma 372-0834, Japan

E-mail:m08702101@gunma-u.ac.jp

This is an open-access article distributed under the terms of the Creative Commons Attribution Non-Commercial No Derivatives (by-nc-nd) License $<$ http://creativecommons.org/licenses/by-nc-nd/4.0/>. pared to those from the other four occupational groups, and they exhibited the lowest HR as compared to their counterparts, though not statistically significant. We concluded that the perceived health status of unemployed women was similar to that of women engaged in agriculture.

Key words: women's health, perceived health, occupational health, mortality risk

(J Rural Med 2018; 13(1): 57-63)

\section{Introduction}

Occupation is known to affect health ${ }^{1)}$. Mortality rates and poor self-assessments of health have been reported to be substantially higher in groups with lower socioeconomic status $^{2}$. Recently, women's health has received greater attention than before ${ }^{3-5)}$, though most studies on women's health have focused mainly on working women.

Our cohort study was initiated in September 1992 by Shosuke Suzuki, with a grant from the Gunma Prefectural Government. The baseline study of this cohort recruited 12,630 participants aged 40-69 years living in two areas, Komochi Village and Isesaki City, in Gunma Prefecture, which is approximately $100 \mathrm{~km}$ to the north of Tokyo, Japan. These areas are included in the metropolitan area; the village had a population of 12,141 , with 3,284 households, and the city had a population of 120,236 , with 40,335 households, according to the 1995 census.

The baseline study was called the Komo-Ise Cohort Study ${ }^{6}$. Based on this baseline study data, Ohta et al..$^{7)}$ identified differences in perceived health, measured by a standardized symptoms checklist called the Todai Health Index (THI, later renamed as the Total Health Index) ${ }^{8}$ ) and in lifestyle between occupational groups among Japanese rural $\mathrm{men}^{7}$. Ohta et $a l^{7}{ }^{7}$ classified the rural men into the follow- 
ing four occupational categories: agriculture and forestry workers, self-employed persons, blue-collared workers, and white-collared workers. They measured the differences in perceived health with reference to other variables such as lifestyle, social network, and job satisfaction, and identified the following significant factors. Agricultural and forestry workers had a lower incidence of obesity, good social networks with relatives and local communities, less subjective physical symptoms, less psychological complaints, and lower job satisfaction as compared to others. The self-employed had higher job satisfaction as compared to others, but they felt that their jobs were difficult. Blue-collared workers had lower job satisfaction, they felt that their jobs were difficult, and they had the highest number of subjective physical symptoms and psychological complaints as compared to others. White-collared workers had the highest incidence of obesity, they ate more Western-style foods, participated in more physical exercise, had higher job satisfaction, did not feel that their job was difficult, had stronger marital relationships, and had lower subjective physical symptoms and psychological complaints as compared to others. However, Ohta et al.'s study ${ }^{7)}$ was based on baseline data and included no information on the number of deaths nor the two integrated scales ${ }^{9}$ in the revised THI.

Subsequently, under the Grant-in-Aid for Scientific Research (No 11694243) provided by the Ministry of Education and Science in 2000, we conducted the first follow-up survey in 2000, which included items on diseases and recorded the deaths; we then conducted a second follow-up survey in 2011 that recorded only the deaths. We identified 1,859 all-cause deaths from 1993 to 2011.

In the present study, we intended to determine the relationship between occupation and health status, including perceived health and mortality, in a cohort of Japanese middle-aged women. For this purpose, we set up a category of unemployed persons including house-wives, which applied to very few men but to approximately $30 \%$ of the middleaged Japanese women ${ }^{10)}$.

\section{Materials and Methods}

The baseline study recruited 12,630 participants who were selected from the registration records of the local government (Jumin-Kihon-Daicho), including 4,875 residents from Komochi Village as of September 1992 and 7,755 residents from the downtown district of Isesaki City as of August 1993. A self-administered questionnaire was distributed through municipal government officers to all eligible participants in Komochi Village in January 1993 and to participants in Isesaki City in October 1993. The completed questionnaires were collected in sealed envelopes through an officially organized community route. In all, 11,565 participants from both areas responded to the questionnaire (response rate: $91.6 \%$ ) during the baseline survey. The first follow-up survey was conducted in 2000, and it included questions on disease as well as an assessment of all-cause deaths and migrations between 1993 and 2000, based on the municipal resident registration files. The second followup survey was conducted in 2011, which assessed all-cause deaths and migration between 2001 and 2011. We followed the rural group from January 1, 1993 to October 1, 2010, and the urban group from October 1, 1993 to September 30, 2011, over a period of 18.8 years (mean follow-up period: 16.0 years). To reduce potential sources of bias, mail and telephone surveys for migrants were conducted from January to March 2001 in the first follow-up survey and from October to December 2011 in the second follow-up survey. We identified 1,859 (1,228 men and 631 women) all-cause deaths. The new Komo-Ise Study database was completed with the results of these follow-up surveys, on January 26 , 2014. The present study was conducted using this new database.

\section{Participants or the women in the cohort}

The 1993 baseline survey data included 11,565 participants (5,630 men and 5,935 women) with valid responses. We identified the occupational status of 4,632 women, 4,454 of whom had information on marital status to be married or unmarried and were included as our study participants.

\section{Variables}

Participants' occupational category was determined based on their response to the question on their longest-held occupation in the 1993 baseline survey. The participants were asked to select one of the following categories: (1) unemployed; (2) agriculture and forestry; (3) shopkeeper; (4) other self-employed; and (5) employee. Based on the responses, we reclassified the women into the following five occupational categories: (1) unemployed persons; (2) agricultural and forestry (hereafter, agriculture) workers; (3) self-employed persons (shopkeepers and other self-employed persons); (4) white-collared workers (based on the description of the employee's work); and (5) blue-collared workers (based on the description of the employee's work).

Marital status and number of generations living in the same household were treated as potential confounders. We divided the marital status of the 4,454 women into married and unmarried. We identified the number of generations living in the same household in 3,315 of these 4,454 women, and the number of generations living in the same household were categorized into one or two generations and three or more generations. 


\section{Data sources}

The self-estimated health of the 4,454 total women was assessed by fourteen scales that most closely represented the participants' perceived health in the standardized symptoms checklist called the $\mathrm{THI}^{8,9)}$.

We first assessed the mortality risks of these 4,454 women based on the 470 all-cause deaths from 1993 to 2011. Subsequently, with respect to the number of generations living in the same household, we assessed the mortality risks in 3,315 of these 4,454 women based on the 299 all-cause deaths from 1993 to 2011.

\section{Quantitative variables}

The $\mathrm{THI}^{8)}$ consists of 130 questions with three response options (1. Often, 2. Sometimes, and 3. Hardly ever or Never), with options 1, 2, and 3 scored as 3, 2, and 1 points, respectively. Lower percentile values indicate better self-estimated health status ${ }^{8)}$. These points are summed within 12 primary scales, which were established by factor analyses. The five scales for physical symptoms are Vague complaints, Respiratory organs, Eyes and skin, Mouth and anus, and Digestive organs. The five scales for mental symptoms are Irritability, Mental instability, Depression, Aggressiveness, and Nervousness. The other two scales are the Lie scale and Irregularity of life. The THI generates five secondary scales (three discriminant values and two integrated scales after applying a principal component analysis to the 12 primary scales) $)^{9}$. Thus, the THI comprises 17 scales. We selected eleven primary scales, two discriminant values, and one integrated scale among these 17 scales to most closely represent the participants' health status ${ }^{9)}$. The selected primary scale of aggressiveness showed an inverse relationship with health as compared with the 10-other primary scales ${ }^{9}$; therefore, we calculated the score for passiveness as $100 \mathrm{mi}$ nus the percentile value of aggressiveness. The 14 selected scales were Vague complaints, Respiratory organs, Eyes and skin, Mouth and anus, Digestive organs, Irritability, Mental instability, Depression, Passiveness, Nervousness, Irregularity of life, Physical stress (Discriminant function value for Psychosomatic characteristics), Mental stress (Discriminant function value for Neurotic characteristics), and Total Scale 1 (the integrated scale).

\section{Statistical methods}

The percentile values of the data in the Komo-Ise Study were calculated using the 2011 revised version of THI plus 05 statistical software. A pairwise t-test on the cumulated percentile values among all the combinations of occupational categories adjusted by the Holm's method was conducted using the R program, version 3.4.1 ${ }^{11)}$.

We estimated the mortality risks, namely, the hazard ratios (HRs) with 95\% confidence intervals (CIs) of the 4,454 women based on the five occupational categories using the Cox proportional hazards model in the R program, version 3.4.11), with the survival package (version 2.41-3). The fits of the Cox model were tested with the likelihood ratio test, Wald test, and Score (log rank) test in the package. Age as of 1993 was entered as a numerical variable in the analysis.

\section{Ethics approval}

Approval was received from The Research Ethics Committee for Epidemiologic Research of Gunma University Graduate School of Medicine (Approval Number 16-5).

\section{Results}

Table 1 shows the basic characteristics and number of generations living in the same household by the five occupational categories based on the baseline survey conducted in 1993 and the deaths from 1993 to 2011.

Table 2 shows the means with standard deviations (SDs) of scale scores and the results of the pairwise t-tests for the 14 THI scales for each occupational category. Lower percentile values indicate better perceived health. The results showed that agricultural workers and blue-collared workers had the best and worst health status, respectively. In the integrated scale of Total Scale 1, the agricultural workers exhibited significantly better health status than did those in the other four occupational categories. The self-employed women who had the lowest score on passiveness and the highest score on irregularity of life were the most stressed (the highest score) according to our new scale assessing mental stress.

Table 2 also presents the differences between the occupations in the irregularity of life scale with prescribed working hours (Self-employed, White collared, and Blue collared) and without prescribed working hours (Agriculture and Unemployed). Among the basic characteristics, agricultural workers had less irregular lifestyles, a higher marriage rate, and a higher frequency of living with three or more generations as compared to others.

In Table 3, we estimated the HRs of the five occupational groups of women adjusted by at most five of the following factors: age, area of residence, irregularity of life scale score, Total Scale 1 score, marital status, and number of generations living in the same household. With any adjustment, the agriculture group showed the lowest HRs among the five job categories, though not statistically significant ( $p$ $>0.05)$. 
Table 1 Basic characteristics and number of generations living in the same household by five occupational categories of a cohort of middle-aged Japanese women based on the baseline survey conducted in 1993, and number of deaths from 1993 to 2011

\begin{tabular}{|c|c|c|c|c|c|c|}
\hline & Agriculture & Unemployed & Self-employed & White-collar & Blue-collar & Sum \\
\hline \multicolumn{7}{|l|}{ Data of the baseline survey conducted in 1993} \\
\hline a) Age distribution as of 1993 (sum) & 439 & 1432 & 1596 & 793 & 194 & 4454 \\
\hline $40 \mathrm{~s}$ & 66 & 386 & 538 & 366 & 77 & 1433 \\
\hline $50 \mathrm{~s}$ & 168 & 441 & 580 & 263 & 79 & 1531 \\
\hline $60 \mathrm{~s}$ & 205 & 605 & 478 & 164 & 38 & 1490 \\
\hline Mean age & 57.7 & 56.1 & 54.0 & 51.6 & 52.3 & 54.6 \\
\hline b) Marital status (sum) & 439 & 1432 & 1596 & 793 & 194 & 4454 \\
\hline Married & 381 & 1223 & 1285 & 599 & 144 & 3632 \\
\hline Unmarried & 58 & 209 & 311 & 194 & 50 & 822 \\
\hline Rate of married $(\%)^{* 1}$ & 87 & 85 & 81 & 76 & 74 & 82 \\
\hline Deaths from 1993 to 2011 in a) and b) & 52 & 180 & 161 & 58 & 19 & 470 \\
\hline c) Number of generations living in the same household (sum) ${ }^{* 2}$ & 314 & 1143 & 1153 & 574 & 131 & 3315 \\
\hline One or two generations & 142 & 873 & 829 & 404 & 91 & 2339 \\
\hline Three or more generations & 172 & 270 & 324 & 170 & 40 & 976 \\
\hline Rate of living with three or more generations $(\%)^{* 3}$ & 55 & 24 & 28 & 30 & 31 & 29 \\
\hline Deaths from 1993 to 2011 in c) & 31 & 123 & 98 & 35 & 12 & 299 \\
\hline
\end{tabular}

${ }^{{ }^{*} 1}$ Married/sum of marital status for each occupational category $\times 100 .{ }^{{ }^{2}}$ We identified the number of generations living in the same household in 3315 of the 4454 women. ${ }^{* 3}$ Three or more generations/sum of number of generations living in the same household for each occupational category $\times 100$.

Table 2 Means, Standard Deviations (SDs), and pairwise t-test of the cumulated percentile values of the scale scores of the Total Health Index (THI) in the five occupational categories of a cohort of middle-aged Japanese women in 1993

\begin{tabular}{|c|c|c|c|c|c|c|c|c|c|c|c|}
\hline \multirow[t]{2}{*}{ Scales of THI } & \multicolumn{2}{|c|}{$\begin{array}{l}\text { 1. Agriculture } \\
(\mathrm{N}: 439)\end{array}$} & \multicolumn{2}{|c|}{$\begin{array}{l}\text { 2. Unemployed } \\
\text { (N: } 1,432)\end{array}$} & \multicolumn{2}{|c|}{$\begin{array}{l}\text { 3. Self-employed } \\
\text { (N: 1,596) }\end{array}$} & \multicolumn{2}{|c|}{$\begin{array}{l}\text { 4. White-collar } \\
\text { (N: 793) }\end{array}$} & \multicolumn{2}{|c|}{$\begin{array}{l}\text { 5. Blue-collar } \\
\text { (N: 194) }\end{array}$} & \multirow{2}{*}{$\begin{array}{l}\text { Pairwise t-test adjusted by } \\
\text { Holm's method }{ }^{* 2}\end{array}$} \\
\hline & Mean & SD & Mean & SD & Mean & SD & Mean & SD & Mean & SD & \\
\hline 1. Vague complaints ${ }^{*}$ & $48.9^{* 1}$ & 28.1 & 52.3 & 27.8 & 54.7 & 28.3 & 52.3 & 28.7 & 55.1 & 28.0 & $1<3^{* 3}$ \\
\hline 2. Respiratory organs & 52.9 & 26.6 & 56.8 & 26.1 & 56.1 & 26.4 & 56.4 & 26.4 & 58.7 & 26.5 & \\
\hline 3. Eyes and skin & 49.5 & 27.0 & 55.0 & 26.8 & 57.0 & 27.2 & 58.6 & 27.3 & 58.9 & 26.6 & $1<2.1<3.1<4.1<5 \quad 2<4$ \\
\hline 4. Mouth and anus & 52.8 & 27.5 & 56.3 & 27.1 & 57.9 & 26.5 & 58.8 & 25.5 & 57.9 & 27.2 & $1<3.1<4$ \\
\hline 5. Digestive organs & 52.8 & 22.8 & 57.8 & 23.4 & 60.0 & 23.2 & 60.5 & 23.4 & 61.2 & 23.7 & $1<2.1<3.1<4.1<5$ \\
\hline 6. Irritability & 46.3 & 28.2 & 52.6 & 28.4 & 54.9 & 28.8 & 56.0 & 28.6 & 57.7 & 29.0 & $1<2.1<3.1<4.1<5 \quad 2<4$ \\
\hline 7. Mental instability & 51.4 & 28.6 & 54.3 & 28.2 & 52.7 & 28.5 & 53.2 & 28.5 & 53.5 & 28.4 & \\
\hline 8. Depression & 50.3 & 26.1 & 56.3 & 26.5 & 56.4 & 26.0 & 56.9 & 25.9 & 57.0 & 25.6 & $1<2.1<3.1<4.1<5$ \\
\hline 9. Passiveness & 46.1 & 29.6 & 45.2 & 28.3 & 41.5 & 28.3 & 42.5 & 29.2 & 48.7 & 29.5 & $3<2.3<54<2.4<5$ \\
\hline 10. Nervousness & 49.1 & 28.1 & 54.0 & 28.4 & 54.7 & 29.5 & 54.6 & 29.9 & 57.5 & 27.7 & $1<2.1<3.1<4.1<5$ \\
\hline 11. Irregularity of life & 42.2 & 25.8 & 50.4 & 27.6 & 59.9 & 27.4 & 59.5 & 27.6 & 59.6 & 28.8 & $\begin{array}{l}1<2.1<3.1<4.1<5 \\
2<3.2<4.2<5\end{array}$ \\
\hline 12. Physical stress *5 & 49.5 & 28.7 & 50.6 & 29.1 & 50.3 & 28.6 & 48.4 & 29.5 & 52.6 & 28.3 & \\
\hline 13. Mental stress ${ }^{* 6}$ & 46.5 & 27.8 & 49.7 & 29 & 51.6 & 28.7 & 49.4 & 29.6 & 51.4 & 27.4 & $1<3$ \\
\hline 14. Total scale $1^{* 7}$ & 43.7 & 28.9 & 50.8 & 28.8 & 52.5 & 28.9 & 53.0 & 29.0 & 56.1 & 28.9 & $1<2.1<3.1<4.1<5$ \\
\hline
\end{tabular}

${ }^{{ }^{* 1}}$ Lower percentile values indicate self-estimated better health conditions. ${ }^{* 2}$ Pairwise t-test on the cumulative percentile values among all the combinations of occupational categories adjusted by the Holm's method was conducted using the R program, version 3.4 .1 . " " $1<3$ " means that there is a significant difference between the left side (1. Agriculture) and the right side (3. Self-employed) at a 5\% level. ${ }^{* 4}$ Scale 1 to 11 are "primary scales," Scale 1 to 5 are "physical scales," and Scale 6 to 10 are "mental scales". "5 "Physical stress" is a psychosomatic tendency, with higher values indicating a higher tendency for the same. " "Mental stress" is a neurotic tendency, with higher values indicating a higher tendency for the same. " "Total Scale 1 " is an integrated scale obtained by applying a principal component analysis to the twelve primary scales. 
Table 3 Occupational Hazard Ratios (HRs) with 95\% Confidence Intervals (CIs) adjusted by age, area of residence, irregularity of life scale score, Total Scale 1 score, marital status, and number of generations living in the same household within the participants of the baseline survey conducted in $1993^{* 1}$

\begin{tabular}{|c|c|c|c|c|c|}
\hline & Agriculture & Unemployed & Self-employed & White-collar & Blue-collar \\
\hline $\begin{array}{l}\text { 1. Adjusted for age, the area of residence : A. } \\
\text { N: } 4,454 \text {; Deaths: } 470\end{array}$ & 1 & $\begin{array}{c}1.29 \\
(0.92 \text { to } 1.81)\end{array}$ & $\begin{array}{c}1.27 \\
(0.89 \text { to } 1.82)\end{array}$ & $\begin{array}{c}1.17 \\
(0.78 \text { to } 1.76)\end{array}$ & $\begin{array}{c}1.53 \\
(0.88 \text { to } 2.66)\end{array}$ \\
\hline $\begin{array}{l}\text { 2. Adjusted for A and Irregularity of life scale. } \\
\text { N: 4,454; Deaths: } 470\end{array}$ & 1 & $\begin{array}{c}1.28 \\
(0.91 \text { to } 1.79)\end{array}$ & $\begin{array}{c}1.24 \\
(0.87 \text { to } 1.78)\end{array}$ & $\begin{array}{c}1.15 \\
(0.77 \text { to } 1.74)\end{array}$ & $\begin{array}{c}1.50 \\
(0.86 \text { to } 2.61)\end{array}$ \\
\hline $\begin{array}{l}\text { 3. Adjusted for A and Total Scale } 1^{* 2} \\
\text { N: } 4,454 \text {; Deaths: } 470\end{array}$ & 1 & $\begin{array}{c}1.27 \\
(0.91 \text { to } 1.77)\end{array}$ & $\begin{array}{c}1.25 \\
(0.87 \text { to } 1.78)\end{array}$ & $\begin{array}{c}1.16 \\
(0.77 \text { to } 1.74)\end{array}$ & $\begin{array}{c}1.50 \\
(0.86 \text { to } 2.60)\end{array}$ \\
\hline $\begin{array}{l}\text { 4. Adjusted for A and marital status. } \\
\text { N: } 4,454 \text {; Deaths: } 470\end{array}$ & 1 & $\begin{array}{c}1.27 \\
(0.91 \text { to } 1.77)\end{array}$ & $\begin{array}{c}1.23 \\
(0.86 \text { to } 1.76)\end{array}$ & $\begin{array}{c}1.10 \\
(0.73 \text { to } 1.65)\end{array}$ & $\begin{array}{c}1.41 \\
(0.81 \text { to } 2.45)\end{array}$ \\
\hline $\begin{array}{l}\text { 5. Adjusted for A and number of generations living } \\
\text { in the same household. } \\
\text { N: } 3315 \text {. Deaths: } 299\end{array}$ & 1 & $\begin{array}{c}1.12 \\
(0.72 \text { to } 1.73)\end{array}$ & $\begin{array}{c}1.06 \\
(0.66 \text { to } 1.69)\end{array}$ & $\begin{array}{c}1.00 \\
(0.59 \text { to } 1.71)\end{array}$ & $\begin{array}{c}1.58 \\
(0.78 \text { to } 3.19)\end{array}$ \\
\hline
\end{tabular}

${ }^{{ }^{*} 1}$ The hazard ratios (HRs) with 95\% confidence intervals (CIs) by the Cox proportional hazards model in the R program, version 3.4.1, with the survival package (version 2.41-3). The fits of the Cox model were tested with the likelihood ratio test, Wald test, and Score (log rank) test in the package. ${ }^{* 2}$ The effect of Total Scale 1 on survival was statistically significant (HR: $1.0035,95 \%$ CI: 1.0004-1.007, p $=0.0281$ ).

\section{Discussion}

Ohta et al.'s study ${ }^{7}$ categorized rural men into four classes; agricultural and forestry (hereafter, agriculture); self-employed; white collared; and blue collared. They applied multiple comparisons to the means of the scores of the 12 primary scales of the THI between occupational groups. The multiple comparisons were conducted with reference to two age groups. One group consisted of men aged 40 to 49 years, and another comprised those aged 50 to 59 years.

In the present study, we applied multiple comparisons to the means of the cumulated percentile values of the scores obtained on the 10 primary scales and the scale on passiveness. Passiveness was calculated as 100 minus the percentile value of aggressiveness as the latter showed an inverse relationship with health as compared with the other primary scales $^{9}$. The multiple comparisons examined the occupational groups of women aged 40 to 69 years.

Owing to these differences between the two studies, we could not simply compare the results of our study with those of Ohta et al.'s study ${ }^{7}$, but there were some differences between men and women.

The largest difference between men and women with reference to the primary scales was that, based on occupational groups, women exhibited significant differences in physical and mental health, with the agriculture and blue collared groups showing the best (the lowest score) and the worst status (the highest score), respectively. Among men, significant differences were mainly observed in the physical scales, and those in the 40s exhibited the best and the worst status with the white-collared and blue-collared groups on the three physical scales (vague complaints, respiratory organs, and digestive organs). For women, there was no significant difference in the scores on the physical scale of respiratory organs. These varying findings may present the differences in the actual jobs of men and women.

Considering the passiveness scale (aggressiveness for men), blue collared women were the most passive, while white collared men were the least passive. Further, self-employed women were the least passive.

With reference to the irregularity of life scale, for men in their $50 \mathrm{~s}$, there were significant differences between agriculture (the best or the lowest score) and blue collared (the worst or the highest score) or self-employed workers (a higher score than agriculture workers). For women, the self-employed and agriculture workers exhibited the worst (the highest) and the best (the lowest) scores among the other groups. However, the unemployed had a lower score than those in the other three groups (self-employed, white collared, and blue collared).

In the study Europe and the US, Clougherty et al. reported that occupations affected health ${ }^{1)}$, and adults with better jobs enjoyed better health; a core finding that has now been replicated in most developed countries ${ }^{1)}$. Further, mortality and poorer self-assessments of health have been reported to be substantially higher in groups with lower socioeconomic status $^{2)}$. However, inequalities in mortality and self-assessed health vary among countries ${ }^{2}$.

In a systematic review undertaken by global search systems such as MEDLINE, between 1999 and 2010 ${ }^{12}$, employed women were found to have more job insecurity, lower control, worse contractual working conditions, and poorer 
self-perceived physical and mental health as compared to $m^{2}{ }^{12)}$. Conversely, employed men had a higher tendency to be engaged in physically demanding work, lower support, higher levels of effort-reward imbalance, higher job status, were more exposed to noise, and worked longer hours than women $\mathrm{did}^{12)}$. This status of employed women and men may be similar to that observed in blue-collared workers in the present study.

In studies comparing the pattern of socioeconomic inequalities in physical functioning and perceived health among male and female public sector employees in Britain, Finland, and Japan"13) — representing "liberal," "Nordic," and "conservative" welfare state regimes, respectively-, broadly similar patterns of differences in health were observed among men ${ }^{13}$. These results reconfirm the pattern of ill-health among those with a lower socioeconomic status among men and women engaging in non-manual work in Britain and Finland ${ }^{13}$. In Japan, the evidence for a socioeconomic gradient in ill-health among men engaging in non-manual work is less systematic, but the poorer health of male manual workers as compared to men engaging nonmanual work is well demonstrated ${ }^{13)}$. However, among Japanese women socioeconomic differences in health were small and inconsistent ${ }^{13}$. For working women, different patterns of labor force participation and welfare provision in different welfare regimes may bring about different patterns of socioeconomic differences in health ${ }^{13}$. This is exemplified by the lack of health inequalities among employed Japanese women ${ }^{13)}$. This lack of health inequalities may imply that the characteristics of Japanese employed women are more homogeneous than are those of employed women other countries.

In the Japanese study called the 2010 Comprehensive Survey of Living Conditions ${ }^{14)}$, the interactive effect of employment contract (permanent or precarious) and household structure (couple only, couple with children, single parent, single person, or other multi-person) on fair/poor health was assessed, and it was found that the interaction effect was significant for women but not for men ${ }^{14)}$. Among female permanent workers, the prevalence of fair/poor health did not differ substantially by household structure ${ }^{14}$. This absence of the effect of household structure on the health status of female permanent workers may be one of reasons why the absence of significant differences in the HR adjusted for number of generations living in the same household in the present study.

Honjo et al. ${ }^{15)}$ investigated the association of employment situation with mortality among 16,692 women aged 40-59 years enrolled in a famous Japanese cohort study (called the Japan Collaborative Cohort Study). They found that, with reference to women working full-time, the mul- tivariate HRs of part-time employees and self-employed workers, after adjustment for mortality, were 1.48 (95\% CI, 1.25 to 1.75$)$ and 1.44 (95\% CI, 1.21 to 1.72$)$, respectively. In the present study, self-employed workers were the most stressed, but there were no significant differences in the HR among the occupational groups. This may suggest that our participants were more homogeneous as compared to those in the study by Honjo et al. ${ }^{15}$.

\section{Conclusion}

Among the five occupational groups of women, agricultural workers showed significantly better perceived health than the other four groups, as evidenced by their scores on the Total Scale 1. Further, self-employed women were significantly more stressed than agriculture women were, and they had the highest score on mental stress. Finally, we found that unemployed women followed the agricultural workers in terms of health status. In general, women engaged in agriculture showed the lowest HRs among the five occupational groups, though not statistically significant.

\section{Acknowledgements}

We thank the NPO of Eco-Health Research Group for the financial support. We thank the mayors and the staff of Shibukawa City, including the area of old Komochi Village and Isesaki City, for their support in conducting the baseline and follow-up surveys.

\section{References}

1. Clougherty JE, Souza K, Cullen MR. Work and its role in shaping the social gradient in health. Ann N Y Acad Sci 2010; 1186: 102-124. [Medline] [CrossRef]

2. Mackenbach JP, Stirbu I, Roskam AJ, et al. European Union Working Group on Socioeconomic Inequalities in Health. Socioeconomic inequalities in health in 22 European countries. N Engl J Med 2008; 358: 2468-2481. [Medline] [CrossRef]

3. Sorensen G, Verbrugge LM. Women, work, and health. Annu Rev Public Health 1987; 8: 235-251. [Medline] [CrossRef]

4. Arber S. Class, paid employment and family roles: making sense of structural disadvantage, gender and health status. Soc Sci Med 1991; 32: 425-436. [Medline] [CrossRef]

5. Artazcoz L, Borrell C, Benach J, et al. Women, family demands and health: the importance of employment status and socio-economic position. Soc Sci Med 2004; 59: 263-274. [Medline] [CrossRef]

6. Suzuki S. Rojin no QOL o kitei suru shinri-shakai yoin no nichi-bei hikaku (Psychosocial factors of QOL of the Aged in Japan and USA 1999-2001). Report of the Grant-in-Aid for Scientific Research (No 11694243), by the Ministry of Education and Science, Japan, 2001 (in Japanese, Abstract in Eng- 
lish).

7. Ohta A, Takeuchi K, Sasazawa Y, et al. Differences in Lifestyle and Perceived Health in Different Occupations in a Community. J Occup Health 1998; 40: 325-333. [CrossRef]

8. Suzuki S, Roberts RE, editors. Methods and applications in mental health surveys: The Todai Health Index. Tokyo: University of Tokyo Press; 1991.

9. Asano H, Takeuchi K, Sasazawa Y, et al. Predictive validity of the total health index for all-cause mortality assessed in the Komo-Ise cohort. J Epidemiol 2008; 18: 68-76. [Medline] [CrossRef]

10. Ministry of Health. Labour and Welfare, Japan. Summary Report of Comprehensive Survey of Living Conditions 2011. Outline of Results, Table 6 Percentage distribution of the job status of persons aged 15 years and over, by sex and age group. p. 8. Available from: http://www.mhlw.go.jp/english/ database/db-hss/dl/report_gaikyo_2011.pdf.

11. The R Development Core Team. The R Project for Statistical Computing. The R Foundation for Statistical Computing, Vienna, Austria. ISBN 3-900051-07-0. [accessed 29 ${ }^{\text {th }}$ August
2017]. Available from: https://www.rproject.org/.

12. Campos-Serna J, Ronda-Pérez E, Artazcoz L, et al. Gender inequalities in occupational health related to the unequal distribution of working and employment conditions: a systematic review. Int J Equity Health 2013; 12-57. [Medline] [CrossRef]

13. Martikainen P, Lahelma E, Marmot M, et al. A comparison of socioeconomic differences in physical functioning and perceived health among male and female employees in Britain, Finland and Japan. Soc Sci Med 2004; 59: 1287-1295. [Medline] [CrossRef]

14. Kachi Y, Inoue M, Nishikitani M, et al. Differences in selfrated health by employment contract and household structure among Japanese employees: a nationwide cross-sectional study. J Occup Health 2014; 56: 339-346. [Medline] [CrossRef]

15. Honjo K, Iso H, Ikeda A, et al. JACC Study Group. Employment situation and risk of death among middle-aged Japanese women. J Epidemiol Community Health 2015; 69: 10121017. [Medline] [CrossRef] 